\title{
HYPOGLOSSAL NERVE PALSY AS THE SOLE MANIFESTATION OF SPONTANEOUS INTERNAL CAROTID ARTERY DISSECTION
}

\author{
Luis Fabiano Marin', Denis Bernardi Bichuetti', André Carvalho Felício', \\ William Adolfo Celso dos Santos', Fabricio Ferreira de Oliveira', Márcia Elisabete Morita', \\ Wagner Mauad Avelar', Pedro Braga-Neto', Elaine Cristina dos Santos Lima', Ricardo Jahn Martins ${ }^{2}$
}

Spontaneous internal carotid artery dissection (ICAD) is now recognized as an important cause of ischemic stroke in patients younger than 45 years of age, with annual incidence ranging from 2.5 to 3.0 per $100000^{1-3}$. The clinical presentation includes unilateral headache or neck pain ipsilateral to the affected carotid artery, Horner's syndrome, transient or complete focal cerebral ischemic deficits, cranial nerve palsy, cervical bruit and tinnitus, which can be associated in various combinations ${ }^{4}$. Isolated cranial nerve palsy is an unusual manifestation of ICAD ${ }^{5,6}$.

We report a patient who presented with a twelfthnerve involvement as the sole clinical sign of ICAD and discuss the mechanisms leading to this finding.

\section{CASE}

A 52-year-old white man was admitted to the emergency department of the Hospital São Camilo Pompéia, Sao Paulo, Brazil, with a 3-hour history of severe headache and facial pain near the angle of the left jaw associated with left-sided deviation of the protruded tongue. There was no history suggestive of head or cervical trauma, nor previous infection. At the emergency room he presented with heart rate $=85 \mathrm{bpm}$, blood pressure $=140 \times 80$ $\mathrm{mmHg}$, normal cardiorespiratory examination and no cervical bruits. The neurological examination disclosed only left hypoglossal nerve palsy (Fig 1). Laboratory work-up, including complete blood count, biochemical tests and glucose were normal. Brain computer tomography was promptly performed and no abnormality was found. Brain magnetic resonance imaging was normal but magnetic resonance angiography and four-vessel cerebral digital subtraction angiography showed a left ICAD arising approximately $4 \mathrm{~cm}$ distal to the carotid artery bulb and extending to the cavernous segment of the artery (Fig 2). An asymptomatic $3 \mathrm{~cm}$ cavernous carotid artery aneurysm was also disclosed by the angiography. The patient was started on heparin in the Intensive Care Unit and maintained on oral anticoagulant (warfarin) after discharge from the hospital. Serological tests (HIV, syphilis, hepatitis B and C), rheumatological tests, vitamin B12, folic acid and homocysteine measurements were all normal. Outpatient follow-up 30 days after symptom onset disclosed an important improvement in tongue movement and there were no

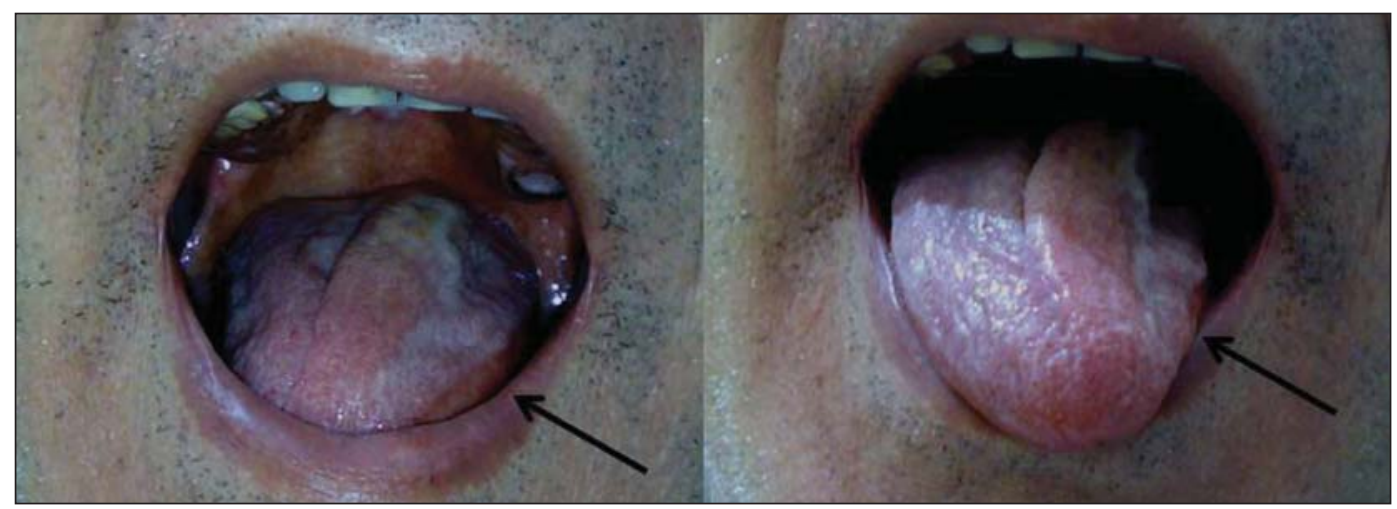

Fig 1. Note the left-sided position of the tongue due to involvement of left hypoglossal nerve (arrow).

\section{PARALISIA DO NERVO HIPOGLOSSO COMO MANIFESTAÇÃO ISOLADA DE DISSECÇÃO DA ARTÉRIA CARÓTIDA INTERNA}

Hospital e Maternidade São Camilo Pompéia, Sao Paulo SP, Brazil: 'Neurology Service; ${ }^{2}$ Radiology Department.

Received 11 September 2008. Accepted 1 December 2008.

Dr. Luís Fabiano Marin - Rua Maranhão 192 / 101 - 01240-000 São Paulo SP - Brasil. E-mail: luisfabianom@gmail.com 


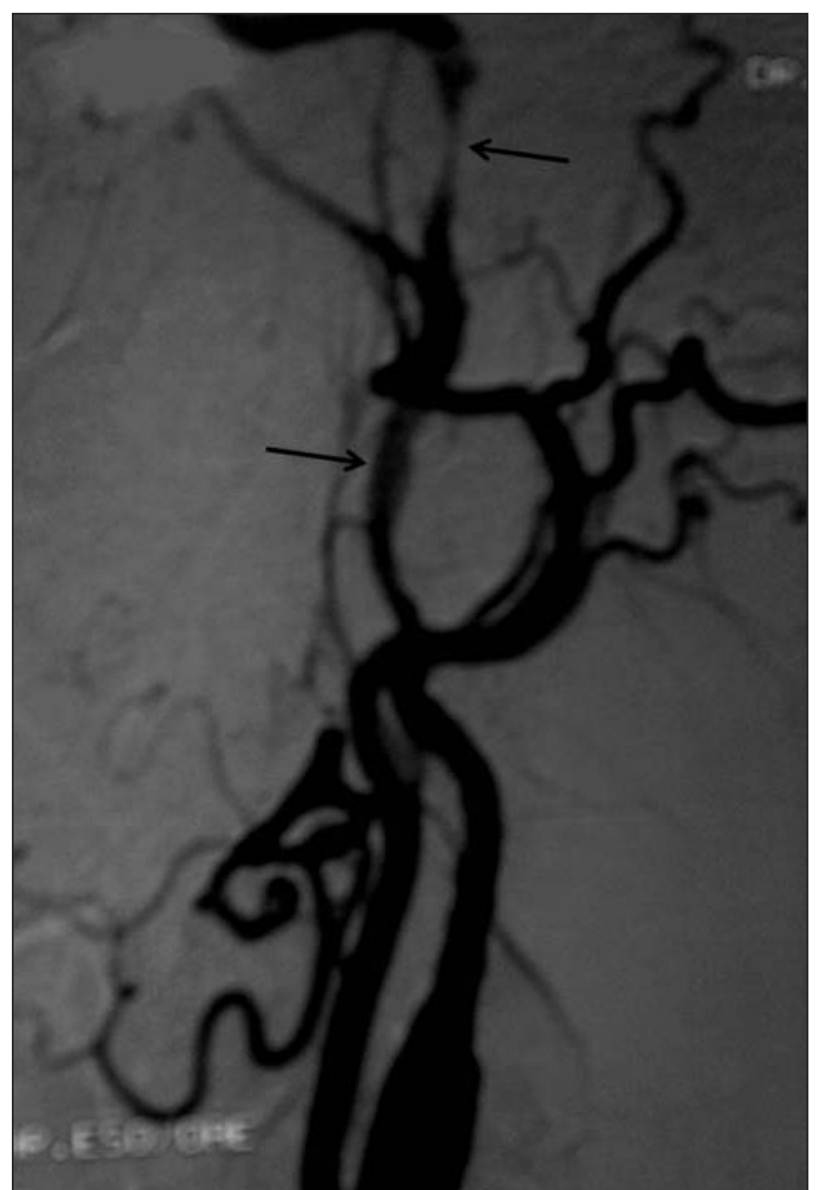

Fig 2. Arrow shows the characteristic pattern of left internal carotid artery dissection.

headache complaints. An informed consent was obtained from the patient to allow data and images publication.

\section{DISCUSSION}

Cranial nerve palsy is an infrequent manifestation of ICAD with the hypoglossal nerve being the most frequently affected ${ }^{5-7}$. Mokri et al. found cranial nerve palsy in 23 of 190 consecutive adult patients (12\%) with ICAD and the hypoglossal nerve was involved in 10 patients $(43 \%)^{6}$.

Twelfth nerve palsy secondary to ICAD frequently occurs associated to focal cerebral ischemic deficits, Horner's syndrome, tinnitus or together with the involvement of other cranial nerves ${ }^{7}$. Lower cranial nerves syndromes (IX, X, $\mathrm{XI}$ and XII) have also been reported in association to ICAD, such as Collet-Sicard and Villaret's syndromes ${ }^{8,9}$. Isolated hypoglossal nerve palsy as the sole manifestation of ICAD as occurred to our patient is an uncommon finding ${ }^{10-12}$.

The underlying mechanism of hypoglossal nerve involvement in ICAD is attributed to mechanical compression or stretching of the cranial nerve below the jugular foramen by the expanded or aneurismal formation of the ICAD. Nevertheless, many arterial dissections have not been clearly associated with aneurysm formation. Other possible mechanism to explain the hypoglossal involvement is related to the blood supply to this cranial nerve. Ischemic injury from nutrient vessels as a result of its anatomic location adjacent to the internal carotid artery mural hematoma might occur by mechanical, embolic or hemodynamic phenomenon ${ }^{7-12}$.

Our patient had no history of trauma preceding the dissection and had no vascular risk factors, infections ${ }^{13}$, or laboratory abnormalities that could explain the ICAD. Digital subtraction angiogram of the left internal carotid artery demonstrated a dilated arterial segment that seems larger in diameter than the original vessel with a stringof-beads appearance along the extracranial length of the internal carotid artery. This feature associated with the 3 $\mathrm{cm}$ cavernous carotid artery aneurysm might be part of the clinical spectrum of fibromuscular dysplasia.

In conclusion, among many disorders that can affect the hypoglossal nerve alongside its nuclear origin to distal rami, it is important to remember ICAD as a differential diagnosis, since it is a severe, but treatable cause of ischemic stroke especially in younger patients.

\section{REFERENCES}

1. Pieri A, Spitz M, Valiente RA, Avelar WM, Silva GS, Massaro AR. Spontaneous carotid and vertebral arteries dissection in a multiethnic population [Portuguese]. Arq Neuropsiquiatr 2007;65:1050-1055.

2. Giroud M, Fayolle H, Andre N, et al. Incidence of internal carotid artery dissection in the community of Dijon. J Neurol Neurosurg Psychiatry 1994;57:1443.

3. Campos CR, Evaristo EF, Yamamoto FI, Puglia P Jr, Lucato LT, Scaff M. Spontaneous cervical carotid and vertebral arteries dissection: study of 48 patients.[Portuguese]. Arq Neuropsiquiatr 2004;62:492-498.

4. Schievink WI, Mokri B, Whisnant JP. Internal carotid artery dissection in a community: Rochester, Minnesota, 1987-1992. Stroke 1993;24:1678-1680.

5. Sturzenegger M, Huber P. Cranial nerve palsies in spontaneous carotid artery dissection. J Neurol Neurosurg Psychiatry 1993;56:1191-1199.

6. Mokri B, Silbert PL, Schievink WI, Piepgras DG. Cranial nerve palsy in spontaneous dissection of the extracranial internal carotid artery. Neurology 1996;46:356-359.

7. Panisset M, Eidelman BH. Multiple cranial neuropathy as a feature of internal carotid artery dissection. Stroke 1990;21:141-147.

8. Vieira VL, Pereira DC, Ribeiro VT, Leite AB, Emerique I. Spontaneous internal carotid artery dissection with paralysis of lower cranial nerves: case report [Portuguese]. Arq Neuropsiquiatr 2006;64:1047-1049.

9. Heckmann JG, Tomandl B, Duhm C, et al. Collet-Sicard syndrome due to coiling and dissection of the internal carotid artery. Cerebrovasc Dis 2000;10:487-488.

10. Urseakar MA, Singhal, BS, Konin, BL. Hypoglossal nerve palsy due to spontaneous dissection of the internal carotid artery. Clin Radiol 2000;978-979.

11. Shahab R, Savy LE, Croft CB, et. al. Isolated hipoglossal nerve palsy due to internal carotid artery dissection. J Laryngol Otol 2001;115:587-589.

12. Lieschke GJ, Davis S, Tress BM, et al. Spontaneous internal carotid artery dissection presenting as hypoglossal nerve palsy. Stroke 1988;19:1151-1155.

13. Felício AC, Silva GS, dos Santos WA, Pieri A, Gabbai AA, Massaro AR. Spontaneous artery dissection in a patient with human immunodeficiency virus (HIV) infection. Arq Neuropsiquiatr 2006;64:306-308. 